\title{
Knowledge of Partograph Recording and Interpretation and Its Documentation Status in Samdrup Jongkhar District, Bhutan
}

\author{
Kuenzang $^{* 1}$, Hari Prasad Pokhrel ${ }^{2}$, Kezang Dorji ${ }^{1}$, Dorji Rinzin ${ }^{2}$, \\ ${ }^{1}$ Dewathang Hospital, Samdrup Jongkhar, Bhutan \\ ${ }^{2}$ Samdrup Jongkhar General Hospital, Samdrup Jongkhar, Bhutan
}

\section{*Corresponding Author}

\author{
Kuenzang \\ Dewathang Hospital, Samdrup Jongkhar, Bhutan \\ E-mail ID: kuenzn2010@gmail.com
}

\begin{abstract}
Background: The study aimed to assess the knowledge of partograph recording and interpretation, partograph utilization and documentation status in the district. Methods: A retrospective study of compiled partographs during the last five years (2013-2017) was conducted to assess the documentation status. This was followed by an intervention study conducted using a self-administered questionnaire. Pretest was conducted to obtain the baseline scores. An intervention in the form educational session on partograph recording and interpretation was conducted which was followed by administration of post-test to obtain the end-line scores. The mean differences in the knowledge scores were compared using paired sample T-test. Results: Over one-third (37.5\%) of the participants reported lack of refresher courses as the key challenge in use of partographs and only $9.6 \%$ of the partographs were found to be complete. Majority $(80.4 \%)$ of them had a poor level of knowledge during the pre-test, which reduced to $7.1 \%$ after the intervention. Paired sample T-test detected significant difference in the mean knowledge scores between the pretest and the post test. Conclusion: Only 54\% of the total deliveries were monitored using a partograph and over $90 \%$ of these partographs were incomplete. Majority of the participants had a poor level of knowledge during the pre-test.
\end{abstract}

Keywords: Knowledge; Partograph; Recording and Interpretation; Samdrup Jongkhar, Bhutan

\section{Introduction}

Partograph is a graphical chart that facilitates monitor the intrapartum period and serves as a reliable tool for the health workers in identifying the complications. ${ }^{[1-3]}$ Partograph is an integral tool comprising of maternal and fetal well-being, progress of labor and medication history which allows for a rapid review during active phase of labor. ${ }^{[4]}$ Over 200 million women become pregnant annually ${ }^{[5]}$ and around 585,000 maternal deaths occur as a result of complications related to pregnancy and childbirth. ${ }^{[6,7]}$ About $99 \%$ of maternal death occurs in developing countries of which $62 \%$ occurs in Sub-Saharan Africa and $24 \%$ in South East Asia. ${ }^{[8]}$ Bhutan made exceptional progress in reducing the maternal deaths from 900 deaths per 100,000 live births in 1990 to 148 in 2015 reflecting an average annual decline of $7.4 \% .{ }^{[8]}$ Despite these reductions, postpartum hemorrhage remains the leading cause of death which is otherwise preventable. ${ }^{[9]}$ The World Health Organization (WHO) recommends that every woman be monitored during the intra-partum period using the WHO modified partograph. ${ }^{[10]}$ An accurate record keeping and interpretation enables effective communication between health professionals aiding in continuity of care. ${ }^{[11]}$ However, studies have reported the lack of knowledge on partograph. ${ }^{[3,12,13]}$ which results in poor utilization. ${ }^{[14-18]}$ Very little is known regarding the knowledge and utilization of partograph in Samdrup Jongkhar District, Bhutan. This study assessed the knowledge of partograph recording and interpretation, partograph utilization in the district and effectiveness of the hands-on training.

\section{Methods}

The study was conducted using two different study designs simultaneously in May 2018. First, a retrospective study of compiled partographs during the last five years (January 2013December 2017) was conducted to assess the documentation status. Total number of deliveries conducted in each health facility was obtained from the birth register maintained at the respective health facility. Delivery cases such as elective caesarean section, emergency caesarean section prior to active phase of labor and women who delivered on the way to health center were excluded from the review. Partographs were reviewed by the investigators and each parameter was recorded as 'Complete' 'Incomplete' or 'Blank' based on the National Standards of Midwifery Practice for Safe Motherhood, 2009. ${ }^{[19]}$ 


\section{International Journal of Innovative Research in Medical Science (IJIRMS) \\ Volume 03 Issue 12 Dec 2018, ISSN: 2455-8737, Imp. Factor - 4.102 \\ Available online at - $\underline{w w w . i j i r m s . i n}$}

This was followed by an intervention study which assessed the knowledge of midwifery trained health professionals (Health Assistants and Nurses) on partograph recording and interpretation. This design was chosen over cross-sectional study to understand the effectiveness of the hands-on training as the requirement of such training was agreed during the annual district health conference conducted on 4th May 2017. All the 12 health facilities in Samdrup Jongkhar were included as study sites. Health professionals who were absent, sick, on leave, trainings and workshops were excluded from the study. Therefore, a total of 56 health professionals working in various health facilities were taken as participants in this study. Data were collected using a validated self-administered questionnaire. A pre-test was conducted to obtain the baseline scores following which an intervention in the form of educational session with hands-on training on partograph recording and interpretation was conducted. Post-test was administered to obtain the end-line scores. Data entry was done using Epi-Data 3.1 and analyzed using SPSS. Descriptive statistics are presented as frequencies, proportions, means, percentages, and standard deviations. Knowledge was classified as 'good', 'moderate' and 'poor' using Benjamin Bloom classification of cognitive skills. Paired sample T-test was used to compare the mean difference in knowledge scores between pre-test and post-test. Ethical clearance was granted by the Research Ethics Board of Health (REBH), Ministry of Health, Thimphu, Bhutan (Ref. No.: REBH/Approval/2017/098). Anonymity of the participants was maintained throughout the study.

\section{Results}

The mean age of the participants was 30 (SD; 7.13) years and over half of them $(55.4 \%)$ were male. Diploma was the highest level of qualification for $60.7 \%$ of the participants and about two-thirds $(66.1 \%)$ of the participants completed their professional education from Bhutan. Over one-third (37.5\%) of them pointed out that lack of refresher course was the main challenge in using the partographs (Table 1).

Table 1: General Information $(\mathbf{n}=56)$

\begin{tabular}{|c|c|c|}
\hline Characteristics & Frequency & Percent \\
\hline \multicolumn{3}{|l|}{ Age } \\
\hline$\leq 29$ & 25 & 44.6 \\
\hline $30-39$ & 22 & 39.3 \\
\hline$\geq 40$ & 9 & 16.1 \\
\hline \multicolumn{3}{|c|}{ Mean 30.00, SD 7.127 } \\
\hline \multicolumn{3}{|l|}{ Gender } \\
\hline Male & 31 & 55.4 \\
\hline Female & 25 & 44.6 \\
\hline \multicolumn{3}{|l|}{ Highest Education } \\
\hline Certificate & 18 & 32.1 \\
\hline Diploma & 34 & 60.7 \\
\hline Bachelors & 4 & 7.1 \\
\hline \multicolumn{3}{|l|}{ Country of Education } \\
\hline Bhutan & 37 & 66.1 \\
\hline India & 18 & 32.1 \\
\hline Thailand & 1 & 1.8 \\
\hline \multicolumn{3}{|l|}{ Number of years in service } \\
\hline $1-5$ years & 32 & 57.1 \\
\hline $6-10$ years & 10 & 17.9 \\
\hline 11 and above & 14 & 25 \\
\hline \multicolumn{3}{|c|}{ Median 4.00, SD 8.462} \\
\hline \multicolumn{3}{|l|}{ Position title } \\
\hline Nurse & 37 & 66.1 \\
\hline Health Assistant & 19 & 33.9 \\
\hline \multicolumn{3}{|l|}{ Challenges in using partograph } \\
\hline No refresher course & 21 & 37.5 \\
\hline Inadequate staff & 16 & 28.6 \\
\hline Inadequate delivery workload & 9 & 16.1 \\
\hline Did not comment & 10 & 17.9 \\
\hline
\end{tabular}

Majority (80.4\%) of the participants had a poor level of knowledge during pre-test which reduced to $7.1 \%$ at post-test (table 2).

Table 2: Knowledge comparison $(n=56)$

\begin{tabular}{lcccc}
\hline Knowledge level & \multicolumn{2}{c}{ Pre-test } & \multicolumn{1}{c}{ Post-test } \\
\hline & n & \% & n & 7.1 \\
Poor (0-9 scores) & 45 & 80.4 & 4 & 7 \\
Moderate (10-12 scores) & 10 & 17.9 & 12.5 \\
Good (13-15 scores) & 1 & 1.8 & 45 & 80.4 \\
\hline
\end{tabular}




\section{International Journal of Innovative Research in Medical Science (IJIRMS) \\ Volume 03 Issue 12 Dec 2018, ISSN: 2455-8737, Imp. Factor - 4.102 \\ Available online at - www.ijirms.in}

The difference in mean knowledge scores between pre-test and post-test was compared by a paired sample T-Test. The mean difference was 5.7 and was found to be statistically significant (Table 3).

Table 3: Mean difference in knowledge score before and after the educational session

\begin{tabular}{lcccccccc}
\hline \multirow{2}{*}{ Activity } & $\mathrm{n}$ & Mean & $\mathrm{SD}$ & \multicolumn{5}{c}{ Mean Difference } \\
\cline { 5 - 9 } & & & & Mean & $\mathrm{SD}$ & \multicolumn{2}{c}{$95 \%$ CI } & $\mathrm{p}$-value \\
\hline Post-test & 56 & 13.13 & 2.00 & 5.70 & 2.93 & 4.91 & 6.48 & 0.000 \\
Pre-test & 56 & 7.43 & 2.24 & & & & & \\
\hline
\end{tabular}

The study observed a huge discrepancy in the number of deliveries recorded and partograph compiled. Only 54\% of the deliveries were monitored using partograph (Table 4).

Table 4: Partograph utilization

\begin{tabular}{lll}
\hline & $\mathbf{n}$ & \multicolumn{1}{c}{} \\
\hline Total deliveries recorded & 1618 & 100.0 \\
Deliveries monitored using partograph & 874 & 54.0 \\
Deliveries not monitored with partograph & 744 & 46.0 \\
\hline
\end{tabular}

Parameter-wise assessment of the compiled partographs showed that fetal well-being was the most incomplete parameter (75.9\%) while $13 \%$ of bio data was blank. Only $9.6 \%$ of the partographs had all the five parameters complete (Table 5).

Table 5: Partograph documentation status $(n=874)$

\begin{tabular}{|c|c|c|c|}
\hline Parameter & Status & $\mathbf{n}$ & $\%$ \\
\hline \multirow{4}{*}{ Bio-data } & Complete & 199 & 22.8 \\
\hline & Incomplete & 561 & 64.2 \\
\hline & Blank & 114 & 13.0 \\
\hline & Total & 874 & 100.0 \\
\hline \multirow{4}{*}{ Fetal Well Being } & Complete & 162 & 18.5 \\
\hline & Incomplete & 663 & 75.9 \\
\hline & Blank & 49 & 5.6 \\
\hline & Total & 874 & 100.0 \\
\hline \multirow{4}{*}{ Progress of Labor } & Complete & 271 & 31.0 \\
\hline & Incomplete & 588 & 67.3 \\
\hline & Blank & 15 & 1.7 \\
\hline & Total & 874 & 100.0 \\
\hline \multirow{4}{*}{ Medication } & Complete & 736 & 84.2 \\
\hline & Incomplete & 125 & 14.3 \\
\hline & Blank & 13 & 1.5 \\
\hline & Total & 874 & 100.0 \\
\hline \multirow{4}{*}{ Maternal Well Being } & Complete & 237 & 27.1 \\
\hline & Incomplete & 605 & 69.2 \\
\hline & Blank & 32 & 3.7 \\
\hline & Total & 874 & 100.0 \\
\hline All parameters Complete & & 84 & 9.6 \\
\hline
\end{tabular}

\section{Discussion}

The study found that most of the plotted partographs did not meet the standard level as required by National Standards of Midwifery Practice for Safe Motherhood, Ministry of Health, Bhutan. ${ }^{[19]}$ Of the 874 partographs reviewed, only $9.6 \%$ were complete or met the standard of approved practice. Studies conducted in nine facilities in Bangladesh, Guinea, Mali, Niger, and Uganda found that less than $5 \%$ of the partographs were complete. ${ }^{[20]}$ Several other studies have reported the poor/incomplete charting of partograph. ${ }^{[2,7,14-18,20]}$ Among the five parameters, fetal wellbeing was the most incomplete. Studies have reported the inadequacies in monitoring of fetal wellbeing using partograph. ${ }^{[14,16,17]}$ The study found that $13.0 \%$ of the bio-data were left blank which is important for patient identification and to reduce confusion. Partographs were full of illegible and unclear handwritings, unapproved symbols and acronyms. This suggest of complacency among the health professionals. Documentation is another form of communication for continuity of care in a clinical set. ${ }^{[11]}$ Poor documentation is suggestive of ineffective communication among health professionals.

Majority of the participants had a poor level of knowledge during the pre-test and over one-third of them pointed that main challenge in utilization of partograph was lack of refresher courses. Similar studies have reported the poor level of knowledge during the pretest. $^{[12,13]}$ Monitoring using partograph during intra-partum is mandatory in Bhutan and the WHO modified Partographs were available in all health facilities but were sub-optimally used. There was a huge discrepency in number of deliveries recorded in birth 


\section{International Journal of Innovative Research in Medical Science (IJIRMS) Volume 03 Issue 12 Dec 2018, ISSN: 2455-8737, Imp. Factor - 4.102 Available online at - $\underline{w w w . j j i r m s . i n}$}

register and compiled partographs. Only 54\% of the deliveries were monitored using the partograph which suggest that the health professionals were unaware about the importance on record keeping for research, innovation and Medio-legal cases. A study conducted in 8 health facilities in south western part of Uganda reported that only $69.9 \%$ of total deliveries were monitored using partograph. ${ }^{[16]}$ Studies conducted in other countries have also reported the poor utilization of partograph. ${ }^{[21,22]}$

The mean difference in the knowledge scores between pre-test and post-test were found statistically significant in this study. This suggest that perodic refresher courses can enhance their understanding of partograph documentation and interpretation. Statistically significant difference between the pre-test and the post-test have been documented in the literature. ${ }^{[12,13,23]}$ Evidences show that health professionals who got on job training performed better than those who did not. ${ }^{[11,24,25]}$ The study had one major limitation. The retrospective component did not measure the outcome of mother and the baby. Positive birth outcomes have been reported when deliveries were monitored using partograph. ${ }^{[7]}$

\section{Conclusion}

Only $54 \%$ of the deliveries were monitored using a partograph and over $90 \%$ of these partographs were incomplete. Majority of the participants had a poor level of knowledge during the pre-test. Refresher courses are essential at regular intervals to improve partograph recording and interpretation. Regular monitoring by the concerned authorities is required to improve the compliance to partograph utilization.

\section{References}

[1] Vlachos G, Tsikouras P, Manav B, Trypsianis G, Vasileios Liberis1, Karpathios S, et al. The effect of the use of a new type of partogram on the cesarean section rates. J Turk Ger Gynecol Assoc 2015;16:145-8.

[2] Bedwell C, Levin K, Pett C, Lavender DT. A realist review of the partograph: when and how does it work for labour monitoring? BMC Pregnancy Childbirth. 2017;17(31):11.

[3] Okokon IB, Oku AO, Agan TU, Asibong UE, Essien EJ, Monjok E. An Evaluation of the Knowledge and Utilization of the Partogragh in Primary, Secondary, and Tertiary Care Settings in Calabar, South-South Nigeria. Int J of Family Med. 2014:9.

[4] Khonje M. Use and documentation in Urban Hospitals in Lilongwe- Malawi: Health Workers' perspective. International Community Health: University of Oslo; 2012.

[5] Bazirete O. Utilization of partogram among nurses and midwives in Rwamagana health facilities in eastern province of Rwanda: University of the Western Cape; 2014.

[6] Bazirete O, Mbombo N, Adejumo O. Utilisation of the partogram among nurses and midwives in selected health facilities in the Eastern Province of Rwanda. AOSIS. 2017;40(1):a1751.

[7] Kitila SB, Gmariam A, Molla A, Nemera G. Utilization of Partograph during Labour and Birth Outcomes at Jimma University. J Preg Child Health 2014;1(1).
[8] World Health Organization. Trends in maternal mortality: 1990 to 2015. WHO Document Production Services, Geneva, Switzerland; 2015.

[9] Ministry of Health, Bhutan. Standard Guideline for management of postpartum hemorrhage. 2nd ed: Reproductive Maternal and Neonatal Health programme, Department of Public Health, Ministry of Health, Thimphu, Bhutan; 2016.

[10] World Health Organization. To improve maternal health, barriers that limit access to quality maternal health services must be identified and addressed at all levels of the health system. In: Department of Reproductive Health and Research WHO, editor. 2014.

[11] Asibong U, Okokon IB, Agan TU, Oku A, Opiah M, Essien E, et al. The use of the partograph in labor monitoring: a cross-sectional study among obstetric caregivers in General Hospital, Calabar, Cross River State, Nigeria. Int J Womens Health. 2014;6.

[12] Prem A, .M.V S. Effectiveness of individual teaching on Knowledge regarding partograph among staff nurses working in maternity wards of selected hospitals at Mangalore. IJRSR. 2013;4(7):1163-6.

[13] Saviola A, A RS, MC M. Effectiveness of a Planned Teaching Program on Knowledge and Skill in the Use of Partograph among Nurses Working in Maternity Unit. South Asian Federation of Obstetrics and Gynecology. 2009;1(2):57-9.

[14] Mandiwa C, Zamawe C. Documentation of the partograph in assessing the progress of labour by health care providers in Malawi's South-West zone. Reprod Health 2017;14:134.

[15] Markos D, Bogale D. Documentation status of the modified World Health Organization partograph in public health institutions of Bale zone, Ethiopia. Reprod Health. 2015;12(81):6.

[16] Ogwang S, Karyabakabo Z, Rutebemberwa E. Assessment of partogram use during labour in Rujumbura Health Sub District, Rukungiri District, Uganda. Afr Health Sci 2009;9(1).

[17] Willi W, Molla M. Partograph chart use among obstetric caregivers in public health institutions of West Shewa Zone, Oromia Regional state, Ethiopia. EJRH. 2017;9(1):36-44.

[18] Yisma E, Dessalegn B, Astatkie A, Fesseha N. Completion of the modified World Health Organization (WHO) partograph during labour in public health institutions of Addis Ababa, Ethiopia. Reprod Health 2013;10(23).

[19] Ministry of Health, Bhutan. National Standards of Midwifery Practice for safe Motherhood. 3rd ed: Reproductive Health Programme, Department of Public Health, Ministry of Health: Thimphu, Bhutan; 2009.

[20] Landry E, Pett C, Fiorentino R, Ruminjo J, Mattison C. Assessing the quality of record keeping for cesarean deliveries: results from a multicenter retrospective record review in five low-income countries. BMC Pregnancy Childbirth 2014;14:139.

[21] Masika MA, Katongole SP, Govule P. Improving Partograph Documentation and Use by Health Workers of Bwera Hospital: A Process Improvement Research. 
International Journal of Nursing and Health Science. 2015;2(4):37-45.

[22] Chaturvedi S, Upadhyay S, Costa AD, Raven J. Implementation of the partograph in India's JSY cash transfer programme for facility births: a mixed methods study in Madhya Pradesh province. BMJ Open 2015;5:e006211.

[23] Al-Dainee MMH, Karim WA, Yasir AA. Effect of the Teaching Program Regarding Partograph on Midwives
Knowledge at Delivery Room in Karbala City Hospitals. Kufa Journal for Nursing Sciences 2016;6(1).

[24] Wakgari N, Tessema GA, Amano A. Knowledge of partograph and its associated factors among obstetric care providers in North Shoa Zone, Central Ethiopia: a cross sectional study. BMC Res Notes 2015;88:407.

[25] Zelellw DA, Tegegne TK, Getie GA. Knowledge and Attitude of Obstetric Care Providers on Partograph and Its Associated Factors in East Gojjam Zone, Northwest Ethiopia. Adv Med. 2016. 